\title{
The role of the nurse in diagnostic and therapeutic procedures in allergology
}

Maja Čamernik, Dolores Pivk, Monika Tomazin, Mateja Hren

\section{Izvleček}

V zadnjih letih opažamo porast alergijskih bolezni, kar je verjetno posledica spremenjenega načina življenja in sprememb naravnega okolja. Po evropskih podatkih ima alergijsko bolezen že več kot 30 \% ljudi. Največkrat se težave začnejo v zgodnjem otroštvu in v mladosti. $Z$ leti se večina alergijskih bolezni ublaži ali celo izgine, nekatere pa lahko trajajo tudi do poznih let ali celo vse življenje. Kažejo se kot alergijski rinitis, astma, alergijski konjunktivitis, koprivnica, alergija na strup (pik) žuželk ter kot preobčutljivost na zdravila in hrano. Lahko se odrazijo tudi kot nevarna sistemska alergijska reakcija, tj. anafilaksija.

Hkrati s pogostostjo alergij se uspešno razvija tudi klinična alergologija z modernimi metodami diagnosticiranja in zdravljenja. V obeh segmentih ima medicinska sestra (MS) pomembno vlogo $v$ multidisciplinarnem timu. Aktivno je udeležena tako pri diagnosticiranju kot tudi zdravljenju alergij, v zadnjem času tudi na področju raziskovanja in uvajanja novosti pri obvladovanju alergijskih bolezni.

Vlogo MS v alergologiji odraža kompleksnost oskrbe bolnika z alergijo, saj vključuje izvrševanje diagnostičnih postopkov in zdravljenja po naročilu zdravnika, zdravstvenovzgojno delo ter skrb za bolnika s kroničnimi alergijskimi težavami (rinitis, atopijski dermatitis) in akutnimi alergijskimi dogodki (anafilaksija).

Ključne besede: vloga medicinske sestre, alergija, diagnosticiranje, zdravljenje.

\section{Abstract}

In the last few years, there has been a significant increase in allergic conditions, probably due to changes in lifestyle and the natural environment. According to European data, over $30 \%$ of the population has allergies. These symptoms usually begin in early childhood and adolescence. Over the years, most allergies are alleviated or even disappear, but others last throughout adulthood or are lifelong. Allergy symptoms and signs present as allergic rhinitis and conjunctivitis, asthma, urticaria, allergy to insect venom (bites) and food allergies and drug hypersensitivity. In addition, they can occur as severe systemic allergic reactions - anaphylaxis.

Together with the increased frequency of allergies, clinical allergology has also successfully developed. Modern diagnostic and therapeutic methods are available. In both segments, the nurse plays a significant role as a member of a multidisciplinary team. The nurse is actively involved in allergy diagnostics and treatment, and recently in research and the implementation of innovations in the management of allergic disease.

Nursing roles within allergology reflect the complex care of patients with allergic conditions. They include performing assigned diagnostic procedures and treatment, ordered by the doctor, patient health education, care of patients with chronic allergic conditions (rhinitis, atopic dermatitis) and acute difficulties (anaphylaxis).

Key words: nurse's role, allergy, diagnostic, treatment. 


\section{Uvod}

V zadnjih letih opažamo porast alergijskih bolezni, kar je posledica načina življenja in sprememb naravnega okolja. Po evropskih podatkih ima alergijsko bolezen že več kot $30 \%$ ljudi. Alergijske bolezni so posledica neugodnega učinkovanja različnih dejavnikov, kot so dedni pogoji, otrokovo splošno zdravstveno stanje ter izpostavljenost otroka alergenom in drugim dejavnikom tako domačega kot zunanjega okolja.

Največkrat se težave začnejo $v$ zgodnjem otroštvu in mladosti. Z leti se večina alergijskih bolezni ublaži ali celo izgine, vendar lahko nekatere trajajo do poznih let ali celo vse življenje.

Hkrati s pogostostjo alergij se vse bolj razvija tudi klinična alergologija, ki nudi moderne metode diagnosticiranja in zdravljenja. $V$ obeh segmentih ima medicinska sestra (MS) pomembno vlogo $v$ multidisciplinarnem timu. Aktivno sodeluje pri diagnosticiranju in zdravljenju alergij, v zadnjem času pa tudi na področju raziskovanja in uvajanja novosti pri obvladovanju alergijskih bolezni.

Alergije so preobčutljivostni odzivi organizma na določene snovi (alergene) iz okolja. So neprijetne, lahko tudi smrtno nevarne. Znaki alergijske reakcije se pojavijo praviloma kmalu po stiku z alergenom. Najbolj pogosti alergeni iz okolja so prehranski in inhalatorni alergeni, strupi (piki) žuželk, zdravila in lateks.

Pogostost alergijskih bolezni se $v$ zadnjih letih hitro povečuje. Spekter alergijskih bolezni je zelo širok. Kažejo se kot alergijski rinitis, astma, alergijski konjunktivitis, koprivnica, alergija na strupe (pik) žuželk ter preobčutljivost na zdravila in hrano, lahko tudi kot nevarna sistemska alergijska reakcija, tj. anafilaksija.

Pri diagnosticiranju in zdravljenju so na voljo moderne metode in sodobna zdravila.

\section{Medicinska sestra v alergologiji}

Alergologija je področje, kjer ima MS pomembno vlogo $v$ multidisciplinarnem timu. Njena vloga vključuje:

- skrb za bolnika z alergijsko boleznijo;

- zdravstvenovzgojno delo za bolnika in starše;

- znanje in veščine, ki so potrebne za opravljanje diagnostičnih postopkov;

- znanje in veščine, ki so potrebne za opravljanje terapevtskih postopkov;

- znanje in veščine, ki so potrebne za prepoznavo in reševanje alergijskih reakcij (vseh stopenj);

- zmožnost vključitve v tim in (so)delovanja v timu;

- organizacijske, administrativne in komunikacijske veščine za dobro sodelovanje z bolnikom in starši;

- željo po izobraževanju in raziskovanju na področju alergologije in zdravstvene nege (ZN).

Vse našteto je potrebno v kliničnem okolju, da lahko MS s sodelavci v timu deluje v dobro bolnika.

\section{Alergijske reakcije na zdravila}

Svetovna zdravstvena organizacija (SZO) nezaželeno reakcijo na zdravila opredeljuje kot škodljiv in nenameren odgovor organizma na zdravilo, ki se uporablja v terapevtskem odmerku. Termin vključuje vse nenamerne nezaželene dogodke, ki jih povzroča določeno zdravilo, ne glede na vpletene patogene mehanizme. Reakcija na zdravila je skupek vseh nezaželenih dogodkov, ki se pojavijo v obdobju uporabe zdravila $(1,2)$.

Alergijske reakcije na zdravila so podskupina imunoloških preobčutljivostnih reakcij, ki so posredovane bodisi s specifičnimi protitelesi IgE ali s specifičnimi limfociti T. Zaradi t. i. imunskega spomina je lahko alergijska reakcija ob ponovnem stiku $z$ alergenom (zdravilom) bolj silovita. Večine alergijskih reakcij na zdravila v nasprotju z alergijo na hrano ali strup žuželk v klinični praksi ne moremo dokazati z obstoječimi alergološkimi testi in vivo in in vitro (3).

Po podatkih staršev otrok je razširjenost (prevalenca) preobčutljivostnih reakcij na zdravila pri otrocih $10 \%$, a je razširjenost pravih alergijskih reakcij na zdravila ob poglobljeni alergološki obravnavi še nižja. V otroški dobi so najpogostejši povzročitelj alergijskih reakcij, povezanih z zdravili v otroški dobi, betalaktamski antibiotiki. V klinični sliki se manifestirajo z znaki in simptomi, ki segajo od urtikarijskega izpuščaja do življenje ogrožajoče anafilaktične reakcije. Zdravila so tretji najpogostejši vzrok anafilaksije pri otrocih (2).

Pri postavitvi diagnoze uporabljamo enake diagnostične meritve in postopke pri odraslih in pri otrocih. Diagnosticiranje je kompleksno in obsega anamnestične podatke o klinični manifestaciji reakcije, kožne teste, laboratorijske teste (če so na voljo in validirani) in provokacijski test z izbranim zdravilom. Izvedba kožnih vbodnih, predvsem intradermalnih testov, ki so sicer bolj občutljivi kot vbodni testi, je za otroke pri otrocih velik problem. Izvedba testov je namreč boleča in jih otroci, predvsem majhni, težko prenašajo. Bolj priporočljivi so provokacijski testi z izbranim zdravilom in brez predhodnega kožnega testiranja (2).

Pri otroku z reakcijo anamnezo navadno podajajo starši ali skrbniki, zato je lahko netočna ali pretirana. Ker se otroci še ne znajo ustrezno izražati, največkrat sami težko opišejo klinično sliko. Fotografije stanja so lahko v veliko pomoč pri razumevanju resnosti reakcije (2).

Kožni testi vključujejo vbodne, intradermalne in krpične teste. So boleči in zato pri otrocih manj zaželeni, a so varni in z malo sistemskimi reakcijami med 
testiranjem. Kožni testi so standardizirani predvsem za odrasle in prenešeni na otroke, za katere specifičnih smernic ni (2).

Z laboratorijskimi testi pri otrocih in pri odraslih največkrat dokazujemo specifična protitelesa IgE za določeno zdravilo. Občutljivost je omejena, zato so za določanje protiteles IgE primerne spojine z majhno molekulsko maso (penicilin V, ampicilin, cefaclor itd.) ali beljakovinski polimeri (inzulin, tetanusni toksoid itd.). Če specifičnih protiteles IgE ne moremo določiti ali je izvid negativen, lahko opravimo dodaten test, npr. test aktivacije bazofilcev (BAT) in test transformacije limfocitov (TTL), ki ga uporabljamo za dokaz poznih alergijskih reakcij na zdravila. Ker gre za draga imunološka testa, ju uporabljamo v manjši meri (2).

Provokacijski testi so zlasti pomembni pri otrocih, saj je velika verjetnost, da bodo poglavitni povzročitelji reakcij (antibiotiki, paracetamol in ibuprofen) še velikokrat potrebni za zdravljenje. Ker so terapevtski oz. dnevni odmerki za otroke odvisni od telesne mase in starosti, tudi ostale odmerke za provokacijo izračunamo individualno. Paziti moramo, da ne prekoračimo dnevnega odmerka in da provokacijski test opravimo v skladu z dogovorjenim protokolom. S provokacijskim testom želimo potrditi ali ovreči alergijo na določeno zdravilo oz. poiskati varno alternativo za morebitno kasnejšo uporabo (2).

Edini uspešen način zdravljenja alergije na zdravila je izogibanje zdravilu, ki je povzročilo reakcijo, in tudi navzkrižno reaktivnim zdravilom. Pri otrocih je to težje izvedljivo, saj je zaradi omejitev predpisovanja na voljo manj alternativnih zdravil (2).

\section{Vloga medicinske sestre}

Vloga MS pri obravnavi bolnika $z$ alergijo na zdravila je tako na področju diagnosticiranja in zdravljenja kot na področju zdravstvene vzgoje in organizacije dela.
Na področju diagnosticiranja MS izvaja alergološke kožne vbodne in intradermalne teste, odvzeme krvi, oralne, podkožne in intravenske provokacijske teste $z$ zdravili ter daje zdravila po desenzibilizacijski shemi.

Na področju zdravljenja mora MS prepoznati znake alergijske reakcije in pravilno ukrepati. Vedeti mora, kako pripraviti in aplicirati zdravila, ki jih predpiše zdravnik. Poznati mora protokole za izvajanje imunoterapije, pripravke, ki se uporabljajo, ter njihove odmerke in dajanje.

Zdravstvenovzgojno delo ima v alergologiji velik pomen, saj moramo otroke in njihove starše naučiti živeti z alergijo na hrano, zdravila ali strupe kožokrilcev. $V$ ta okvir sodijo tudi dietno svetovanje, svetovanje glede izogibanja alergenom v okolju in učenje ustreznega ukrepanja ob alergijski reakciji.

\section{Provokacijski testi pod nadzorom}

Nadzorovano uvajanje živila ali zdravila imenujemo provokacijski test oz. peroralni test in je najbolj zanesljiv klinični postopek za diagnosticiranje alergije na hrano ali zdravilo (4). Ostali alergološki testi (kožni in krvni testi) niso vedno zanesljivi za dokončno opredelitev alergije na hrano ali zdravilo.

Če obstaja možnost alergijske reakcije na hrano ali zdravilo, slednje uvedemo pod nadzorom v bolnišnici. S provokacijskim testom ugotovimo, ali lahko otrok uživa testirano živilo ali ne. Pri otrocih alergija na določena živila pogosto postopno izzveni oz. jo otroci prerastejo, ker dosežejo toleranco. Ta živila lahko nato uživajo brez težav (4). Pri zdravilih je zelo pomembna opredelitev, ali je otrok na zdravilo res preobčutljiv, saj velja preobčutljivost vse življenje in vpliva na odločitve o morebitnem nadaljnjem zdravljenju (5).

Otrok mora biti za provokacijsko testiranje zdrav in v zadnjem obdobju brez izrazitih poslabšanj alergijske bolezni (atopijski dermatitis). Pri provokaciji na hrano otrok tri dni pred testiranjem ne sme prejemati antihistaminikov, pri provokaciji na zdravila pa je to obdobje pet dni. Prav tako ne sme prejemati sistemskih kortikosteroidov ali olajševalcev za astmo. Rednega jemanja zdravil za astmo, alergijski rinitis in atopijski dermatitis ne smejo prekiniti $(5,6)$.

\section{Provokacijski test na hrano}

Provokacijsko testiranje za posamezno živilo v bolnišnici lahko traja en dan ali dva dni. Izbira protokola mora temeljiti na varnosti in natančnosti. Poznati moramo dejstva o zgodovini alergijske reakcije pri bolniku, dana podlagi teh informacij določimo protokol (4). Provokacijski test pričnemo z najnižjim odmerkom izbranega živila, ki ga postopno in $\mathrm{v}$ skladu $\mathrm{s}$ protokolom povečujemo v 30-minutnih intervalih. Hrana mora biti toplotno obdelana. Pri določenih bolnikih s provokacijskim testom potrdimo, da lahko živilo varno uživajo le v manjših količinah.

Ob pojavu znakov alergijske reakcije med provokacijo $v$ bolnišnici s provokacijo prekinemo in otrok dobi po potrebi zdravila za zdravljenje alergijske reakcije. Če so težave med izvajanjem provokacije v bolnišnici neprepričljive oz. dvomljive, s testom običajno nadaljujemo. Težave ob izvajanju testa se lahko pojavijo zaradi vpliva številnih, za otroka neugodnih dejavnikov (stres ob sprejemu v bolnišnico, sprememba $v$ temperaturi in vlažnosti zraka).

Itok in Urisu (4) sta navedla, da je provokacijski test bolj primeren za dojenčke in majhne otroke, saj s testiranjem še niso psihološko obremenjeni. Starejši otroci lahko navajajo subjektivne znake težav. Subjektivni znaki (bruhanje, pekoč jezik, nelagodje $v$ trebuhu, srbenje sluznic in kože brez vidnih sprememb) so lahko tudi psihične narave. Otrok, ki ni vajen določenega živila zaradi dolgotrajne diete, morda živilo odklanja tako v bolnišnici kot doma, kar otežuje uspešno izvedbo provokacijskega testiranja (6). 


\section{Provokacijski test na zdravila}

Določimo zdravilo za provokacijo, način dajanja zdravila, odmerek zdravila in časovne intervale med odmerki zdravila, morebitno nastavitev intravenskega kanala itd. Zdravilo začnemo dajati na predpisani način v najnižjem odmerku, nato pa odmerek na 60 minut stopnjujemo do običajnega terapevtskega odmerka (5).

\section{Vloga medicinske sestre}

Za učinkovito in varno izvedbo provokacijskega testa je nujno timsko sodelovanje vseh zdravstvenih delavcev in prevzemanje odgovornosti za svoje delo. Odmerke zdravila ali živila opredeli zdravnik - predpiše zdravilo ali živilo, odmerek, pogostost dajanja oz. časovne intervale med odmerki in način dajanja. V izogib napakam lahko MS zahteva, da je naročilo napisano popolno, pravilno in čitljivo. Zdravnik lahko protokol prilagodi tudi posameznemu bolniku, in sicer glede na anamnestične podatke o alergijski reakciji, laboratorijske izvide ter stanje in sodelovanje otroka in staršev.

Ne glede na to, ali gre za provokacijsko testiranje s hrano ali zdravili, se mora MS držati pravil 10P in protokola provokacijskega testa. MS so odgovorne za pravilno in varno dajanje predpisanih živil ali zdravil v kakršnikoli obliki in morajo zagotavljati, da pravi bolnik prejme pravi odmerek pravega zdravila ali živila v pravi obliki, na pravilen način, ob pravem času, v pravilnih časovnih razdobjih, v predpisanem trajanju zdravljenja ter ob pravilnem nadaljnjem opazovanju za zagotavljanje varnosti in učinkovitosti zdravljenja. Vsi zdravstveni delavci moramo poročati tudi o nezaželenih učinkih zdravil in napakah pri dajanju.

MS mora poznati posamezna zdravila in način njihovega dajanja ter živila, s katerimi bo izvajala provokacijsko testiranje. Do napak pri izračunu odmerkov lahko pride zaradi neobvladovanja osnovnih matematičnih operacij in/ali nezmožnosti, da izlušči ustrezne informacije in pri računanju uporabi prave računske operacije.

Ne glede na to, ali bolnik prejel neustrezen odmerek zdravila zaradi nepravilnega izračuna in/ali napak v procesu dajanja, sta ogroženi klinična učinkovitost provokacijskega testa in bolnikova varnost.

\section{Anafilaksija}

Anafilaksija je resna, življenje ogrožajoča, generalizirana ali sistemska preobčutljivostna reakcija, ki se razvije v nekaj minutah ter se kaže s simptomi in znaki prizadetosti dihal in srčno-žilnega sistema (7). Pri otrocih v šolskem obdobju anafilaksijo najpogosteje povzročajo živila, kot so arašidi, drevesni oreščki in kravje mleko ter tudi žuželke, zdravila, lateks in telesna vadba (8). Letna pojavnost anafilaksije se med državami razlikuje. Ocenjujejo, da jo v Združenem kraljestvu utrpi 10,2/100.000 ljudi. Ocenjena razširjenost hude anafilaksije $v$ Švici in Združenih državah Amerike znaša 0,51/10.000, na Švedskem, v Budimpešti, Barceloni in Bombaju pa je nekaj večja od 1,5/10.000 (9). V Sloveniji pojavnost anafilaksije pri otrocih ocenjujejo na $0,19-50 / 100.000$ otrok letno in se $v$ zadnjih letih povečuje, predvsem na račun alergij na hrano (7).

\section{Najpogostejši povzročitelji anafilaksije}

Reakcije, ki jih povzroča hrana, predstavljajo več kot polovico (55,3\%) vseh reakcij. Med prehranskimi reakcijami je največ reakcij povezanih z arašidi $(18,4$ $\%), 13,4$ \% reakcij pa z živili neznanega izvora (10). V ZDA so v raziskavi ugotovili, da so pri $90 \%$ vseh prehranskih alergijskih reakcij vzrok kravje mleko, jajca, arašidi, drevesni oreščki, pšenična moka, soja, ribe in školjke. Reakcije segajo od blagih do hudih in lahko vodijo do anafilaksije, hude, potencialno smrtne sistemske alergijske reakcije, ki se pojavi nenadno in lahko povzroči smrt (11).

\section{Zdravljenje}

Zdravilo prve izbire je adrenalin. Takoj, ko postavimo utemeljen sum na anafilaksijo, ga vbrizgamo v mišico. To storimo vedno, ko so prisotni simptomi in znaki prizadetosti dihal ali srčno-žilnega sistema, in sicer hripavost, lajajoč kašelj, težko požiranje, stridor, dispneja, zmerno piskanje, cianoza, prenehanje dihanja, hipotenzija, kolaps, huda bradikardija in/ali odpoved srca (7). Anafilaksija zahteva hitro ukrepanje, $\mathrm{s}$ čimer preprečimo zaplete in morebitno smrt. Izsledki raziskav kažejo, da je odloženo zdravljenje $z$ adrenalinom glavni dejavnik tveganja smrti zaradi anafilaksije (12). Primerna lega otroka ob anafilaksiji je leže na hrbtu z dvignjenimi nogami (Trendelenburgov položaj), pri težkem dihanju polsedeči položaj, ob bruhanju pa ležeč na boku. Če je možno, prekinemo stik z alergenom (npr. po zaužiti hrani oplaknemo usta, ustavimo infuzijo zdravila, po piku žuželke odstranimo želo). V primeru srčno-dihalne odpovedi izvajamo postopke oživljanja (13).

\section{Vloga medicinske sestre}

Skrb in odgovornost negovalnega osebja do kritično bolne osebe z alergijsko reakcijo je pogojena $z$ visoko stopnjo znanja in usposobljenosti za pravilno, pravočasno, natančno in profesionalno ukrepanje. Zaradi izvajanja več aktivnosti hkrati bolnika obravnava več oseb (14). Ob alergijskih reakcijah bolniku vbrizgamo adrenalin po naročilu zdravnika. Pomembno je, da nadzorujemo srčni utrip in krvni tlak saj lahko pride do motenj srčnega ritma.

Vsak bolnik je individuum. Zato vsak bolnik potrebuje individualno obravnavo, vsakemu se moramo posvetiti in približati na svojstven način. Običajno je bolnika strah, zato MS deluje tudi kot mentor in učitelj, ki z znanjem in izkušnjami ter komunikacijskimi spretnostmi poskuša vzpostaviti zaupanje in spoštovanje do te mere, da bolnik dejavno sodeluje, se v času testiranja počuti varnega ter pred- 
vsem enakovrednega pri načrtovanju in izvajanju testiranja (15). Naloga MS je, da posreduje prave informacije in bolniku pove, kje lahko dobi dodatne informacije in dodatna gradiva. Nauči ga, da prepozna znake alergijske reakcije in načine ukrepanja, ko se pojavijo. Razloži in praktično pokaže, kako uporabljati avtoinjektor adrenalina.

\section{Avtoinjektor adrenalina}

Avtoinjektorji omogočajo enostavno uporabo in jih bolniki v primeru anafilaktične epizode lahko uporabijo sami (16). Avtoinjektor je pripomoček za enkratno vbrizganje adrenalina v zgornji zunanji del stegenske mišice. Uporabimo ga takoj ob pojavu anafilaksije, še pred prihodom ekipe nujne medicinske pomoči (NMP) (13). Adrenalinski avtoinjektorji so pripravljeni za enkratno uporabo. Uporabo svetujemo, če bolnik začuti simptome na dihalih ali srčno-žilnem sistemu. Če je imel bolnik zelo hudo predhodno reakcijo, si lahko vbrizga zdravilo ob pojavu prvih simptomov, s katerimi se je začela prejšnja epizoda. Po vbrizganju moramo bolnika sprejeti v zdravstveno ustanovo na pregled, tudi če so vsi simptomi izginili (17). Ob predpisu avtoinjektorja adrenalina o uporabi izobrazimo otroka, svojce in vse, ki skrbijo za otroka, in jih seznanimo, kdaj in kako ga uporabljamo. Otrokom s telesno težo 7,5-25 kg predpišemo avtoinjektor adrenalina $v$ odmerku $150 \mu$ g, otrokom, težjim od 25 $\mathrm{kg}$, pa v odmerku $300 \mu \mathrm{g}$ (18).

\section{Kakovost življenja}

Pomanjkanje informacij je pomembna ovira pri spopadanju $z$ boleznijo in poslabšuje kakovost življenja. Anafilaksija je življenje ogrožajoče zdravstveno stanje, ki zahteva strogo izogibanje alergenu. Izboljšati moramo izobraževanje bolnikov in svojcev. Ustrezno izobraževalno gradivo o nujni samopomoči in izogibanju alergenom lahko bolnikom, vzgojiteljem in staršem ogroženih otrok pomaga, da razvijejo uspešne strategije spoprijemanja, ki ugodno vplivajo na kakovost življenja (19).

\section{Specifična imunoterapija}

Specifična imunoterapija (SIT) je zdravljenje z IgE posredovanih alergij, kot so alergijski rinitis, alergijska astma in alergija na strupe insektov. SIT je edina oblika zdravljenja, ki spremeni imunski odziv in naravni potek alergijske bolezni. S SIT želimo pri bolniku zmanjšati simptome alergijske bolezni $(20,21)$.

Zdravljenje je specifično, zato moramo prepoznati alergen, ki sproža alergijske simptome. Uvedba zdravljenja s SIT temelji na anamnestičnih podatkih, pregledu bolnika in vlogi alergena kot sprožilca poslabšanja bolezni. Običajno pričnemo SIT z zelo nizkim odmerkom raztopine industrijsko pripravljenega alergena. Odmerek postopno povečujemo do vzdrževalnega odmerka, ki ga bolnik prejema približno enkrat na mesec, vsaj 3-5 let. S ponavljajočim se vnašanjem specifičnega alergena v telo $v$ rednih intervalih izzovemo imunsko toleranco in zmanjšamo klinično odzivnost bolnika ob ponovnem stiku z alergenom. Zdravljenje s SIT začnemo pri bolnikih, pri katerih dokažemo, da je vzrok simptomov specifičen vzročni alergen in pri katerih alergija poteka intenzivno, pri čemer običajna protialergijska zdravila simptomov alergije ne umirijo. Učinki SIT trajajo vrsto let po končanem postopku (22).

Med SIT, ko v telo vnašamo alergen, skušamo po shemi doseči takšno stanje imunskih celic, tj. limfocitov $T$, da bodo celice alergen prepoznale in ga tolerirale. Na ravni T-celičnega odgovora se po uspešni SIT na mestu alergijskega draženja zniža koncentracija limfocitov T in eozinofilcev. Spremeni se tudi citokinski profil. Imunoterapija spodbudi regulatorne limfocite $\mathrm{T}$, ki preko izločanja antiinflamatornih citokinov povzročajo tvorbo blokirajočih protiteles IgG, in zmanjša tvorbo protiteles IgE (23).

V klinični praksi izvajamo SIT na dva načina - s podkožno imunoterapijo (SCIT) in podjezično imunoterapijo (SLIT). Oba načina a sta učinkovita pri zmanjševanju simptomov alergije, potrebe po antialergijskih zdravilih in nevarnosti redkih sistemskih reakcij.

SCIT sta prvič izvedla Noon in Freeman pred več kot 100 leti, ko so bolnike $z$ alergijo na pelode trav cepili z njihovimi izvlečki (24).

SCIT je bil dolga leta zlati standard pri izvajanju imunoterapije na inhalacijske alergene in strupe kožokrilcev. Danes je podkožna imunoterapija standardna metoda pri bolnikih, ki so alergični na strupe kožokrilcev (25). V današnjem času pri tej obliki imunoterapije alergen vnašamo $v$ telo $s$ podkožnimi (subkutanimi) injekcijami v naraščajočih odmerkih.

Obstajajo različne standardizirane sheme, po katerih lahko dosežemo vzdrževalni odmerek v enem dnevu (t. i. metoda rush), nekaj dneh (t. i. metoda semirush) ali nekaj mesecih (standardni način uvajanja SIT) (26).

SCIT poteka v dveh fazah, začetni in vzdrževalni fazi. V začetni fazi lahko prejemajo nizke odmerke alergena $v$ obliki subkutane injekcije tedensko ali večkrat tedensko. Odmerke v 3-6 mesecih postopno povečamo do vzdrževalnega odmerka (standardni način uvajanja). Začetna faza lahko poteka tudi hitreje, in sicer tako, da naraščajoče odmerke dajemo $v$ dveh, treh ali štirih injekcijah zaporedno $v$ enem dnevu in jih v naslednjih dneh povečujemo ter $v$ nekaj dneh dosežemo vzdrževalni odmerek (metoda rush) $(26,27)$.

Glavna pomanjkljivost hitrega povečevanja odmerka so predvsem pogostejši sistemski nezaželeni učinki, vključno z anafilaktično reakcijo. Zato so bolniki, pri katerih izvajamo začetno fazo SIT po hitri metodi, pod strogim nadzorom $v$ bolnišnici $(26,27)$.

Vzdrževalna faza traja 3-5 let, bolniki pa dobivajo vzdrževalni odmerek na 4-6 tednov (26).

SLIT je nova oblika imunoterapije pri bolnikih, ki so alergični na inhalaciij- 
ske alergene. Pri SLIT alergen nanašamo na ustno sluznico pod jezik v obliki kapljic ali tablet. Tudi pri tej obliki v začetni fazi vnašamo majhne količine alergenov po določeni shemi, dokler ne dosežemo vzdrževalnega odmerka. Bolnik si alergen v začetni fazi in kasneje v vzdrževalni fazi daje vsak dan ali vsak drugi dan, zdravljenje pa poteka tri leta (28).

Indikacija za SLIT in SCIT pri inhalacijskih alergenih je enaka in enako učinkovita. Edina razlika je, da pri SLIT hitreje dosežemo vzdrževalni odmerek, zdravljenje pa je bolj praktično, udobno $v$ domačem okolju, neboleče in z manj nezaželenimi učinki. Pri SLIT so bolj izraženi lokalni nezaželeni učinki, kot sta srbenje $v$ ustih in draženje grla, medtem ko je tveganje sistemske alergijske reakcije pri SLIT zelo majhno.

SLIT in SCIT imata enake kontraindikacije in ju ne izvajamo pri bolnikih z neurejeno astmo, rakavimi boleznimi in avtoimunskimi boleznimi, pri bolnikih, ki se zdravijo z blokatorji beta, in v nosečnosti (28).

\section{Vloga medicinske sestre}

Vloga MS je pri izvajanju SLIT in SCIT ključna. MS je del tima, ki ga vodi zdravnik specialist alergolog. MS mora biti usposobljena za izvajanje SIT ter pridobiti teoretična in praktična znanja in izkušnje, pri delu pa mora biti odgovorna. Na tem področju se mora stalno izobraževati, da pridobi specialna znanja. Imeti mora osnovna znanja alergologije ter poznati in razumeti postopke SLIT in SCIT. Dobro mora opazovati, da pravočasno prepozna nezaželene učinke imunoterapije ter hitro in pravilno ukrepa (29).

Pri izvajanju imunoterapije SCIT mora dobro poznati pripravke alergenov in sheme izvajanja imunoterapije, pripraviti prave koncentracije in odmerke pripravkov ter obvladati tehniko dajanja zdravil. Odgovorna je tudi za vzdrževanje hladne verige pri shranjevanju pripravkov in njihovem naročanju.
Zaradi tveganja nezaželenih učinkov pri izvajanju imunoterapije mora poskrbeti, da so na mestu, kjer poteka imunoterapija, takoj na voljo nujna zdravila za preprečevanja resnih sistemskih reakcij, in jih mora tudi pripraviti in varno uporabiti. Skrbi tudi za dosegljivost in delovanje druge nujne opreme ob potrebi po nujni medicinski pomoči (dotok kisika ipd.) v prostoru, kjer se izvaja imunoterapija (29).

SLIT je zelo praktična metoda izvajanja imunoterapije v domačem okolju. Naloga MS je, da starše in otroke seznani, kako pravilno pripraviti dozirnik alergena in dozirno posodico, kako pravilno nanesti alergen ter kako shranjevati zdravilo in z njim rokovati. MS tudi preveri, ali so starši razumeli shemo zdravljenja, da bodo ob morebitnem pojavu nezaželenih učinkov SLIT znali odmerjati alergen in ustrezno ukrepati (29).

\section{Zaključek}

Glede na veliko pojavnost alergijskih bolezni ter uvajanje novih, modernih metod diagnosticiranja in zdravljenja delo MS ni zgolj sodelovanje pri odkrivanju in zdravljenju. Velik del zadolžitev MS je povezan tudi z izobraževanjem, tako sebe kot drugih (sodelavcev, bolnikov, staršev idr.)

\section{Literatura}

1. World Health Organization. International drug monitoring: the role of national centres. Report of WHO meeting. Tech Rep Ser WHO 1972; 498: 1-25.

2. Gomes ER, Brockow K, Kuvycu S, Saretta F, Mori F, Blanca-Lopez $\mathrm{N}$ et al. Drug hypersensitivity in children: report from the pediatric task force of the EAACI Drug Allergy Interest Group. Allergy 2016; 71(2): 149-61.

3. Schneyder B, Brockow K. Pathogenesis of drug allergy - current concepts and recent insights. Clinical and Experimental Allergy 2015; 45: 1376-83.

4. Itok K, Urisu A. Diagnosis of Food allergy Based on Oral Food Challenge Test. Allergology international 2009; 58: 467-9.

5. Interna navodila UKCLJ. Navodila za starše o provokacijskem testu z zdravili. NP 1423.

6. Interna navodila UKCLJ. Navodila pacientom. Informacije o provokacijskem testu na hrano. NP 1424.
. Zupanc C, Vesel T. Pristop k otroku z anafilaksijo. Slovensko združenje za urgentno. 2016: 181-7.

8. Ercan H, Ozen A, Karatepe H, Berber M, Cengizlier R. Primary school teachers' knowledge about and attitudes toward anaphylaxis. 2012; 23(5): 428-32.

9. Frew AJ. What are the 'ideal'features of an adrenaline (epinephrine) auto-injector in the treatment of anaphylaxis? Allergy 2011; 66(1): 15-24.

10. DeSantiago-Cardenas L, Rivkina V, Whyte SA, Harvey-Gintoft BC, Bunning BJ, Gupta RS. Emergency epinephrine use for food allergy reactions in Chicago Public Schools. American journal of preventive medicine 2015; 48(2): 170-3.

11. Wahl A, Stephens H, Ruffo M, Jones AL. The evaluation of a food allergy and epinephrine autoinjector training program for personnel who care for children in schools and community settings. J Sch Nurs 2015; 31(2): 91-8.

12. Foster AA, Campbell RL, Lee S, Andeson JL. Anaphylaxis preparedness among preschool sta$\mathrm{ff}$ before and afte an educational intervention. $J$ Allergy 2015; 231862

13. Galun S. Naloge medicinske sestre pri različnih šokovnih stanjih pri otrocih. Maribor 2019: Fakulteta za zdravstvo. Dostopno na: https://dk.um.si/Dokument. php?id=11253\&lang=slv.

14. Vesel T, Jeverica KA et al. (2014). Smernice za obravnavo otroka in mladostnika z anafilaksijo. Zdrav Vestn 2014; 83: 425-35.

15. Perko K. Preobčutljivost na hrano - nutritivna alergija. Golnik. Zdravstvena nega pacienta z astmo in alergijo. 2012.

16. Abramson MJ, Puy RM, Weiner JM. Injection allergen immunotherapy for asthma. Cochrane Database Syst Rev 2010; 8: CD001186.

17. Song T, Liberman P. Who needs to carry an epinephrine autoinjector? Cleve Clin J Med 2019; 86(1): 66-72.

18. Košnik M, Zidarn M, Glavnik V et al. Dogovor o obravnavi anafilaksije. Golnik: Sekcija za pediatrično pulmologijo, alergologijo in klinično imunologijo, Slovensko združenje za urgentno medicino, Slovensko združenje za intenzivno medicino, združenje za anesteziologijo in intenzivno medicino, Alergološka in imunološka sekcija SZD. 2015. Dostopna na: http://www.szum.si, 1-16.

19. Vesel T, Jeverica KA, Accetto M, Toplak N, Emeršič N, Kuhar M, et al. Anafilaksija - pogled pediatra. V: Košnik M, Vesel T, Marčun R, ur. Zbornik sestanka: Anafilaksija. Ljubljana, 2014: Alergološka in imunološka sekcija SZD; 33-7.

20. Kastner M, Harada L, Waserman S. Gaps in anaphylaxis management at the level of physicians, patients, and the community: a systematic review of the literature. Allergy 2010; 65(4): 435-44.

21. Shamji MH, Durham SR. Mechanisms of allergen immunotherapy for inhaled allergens and predictive biomarkers. J Allergy Clin Immunol 2017; 140: 1485-98

22. Allergen immunotherapy: an updated review of safety).

23. Gunawardana NC, Stephen R. Durcham. Mechanisms of allergen. V: Cox LS, ur. Immunotherapies for Allergic Disease. Immunotherapy: 117-132.

24. Freeman J. Further observations of the treatment of hay fever by hypodermic inoculations of pollen vaccine. Lancet 1911; 2: 814-7. 
26. Cox L, Nelson H, Lockey R et al. Allergen immunotherapy: a practice parameter third update. J Allergy Clin Immunol 2011; 127 (1): 1-55.

27. Golden DB, Demain J, Freeman T, et al. Stinging insect hypersensitivity: a practice parameter update 2016. Ann Allergy Asthma Immunol 2017; 118 (1): 28-54.

28. Canonica G, Cox L, Pawankar R, et al. Sublingual immunotherapy: World Allergy Organization position paper 2013 update. World Allergy Organ J 2014; $7(1): 6$.

29. Medical-Surgical Nursing - E-Book: Assessment and Management of Clinical ... Po avtorjih Sharon L. Lewis, Linda Bucher, Margaret M. Heitkemper, Mariann M. Harding, Jeffrey Kwong, Dottie Roberts, Chapter 14, str 215 in Chapter 13.

\section{Maja Čamernik, dipl. m. s.}

Klinični oddelek za otroško alergologijo, revmatologijo in klinično imunologijo Pediatrična klinika, Univerzitetni klinični center Ljubljana, Ljubljana, Slovenija

Dolores Pivk, dipl. m. s.

Klinični oddelek za otroško alergologijo, revmatologijo in klinično imunologijo Pediatrična klinika, Univerzitetni klinični center Ljubljana, Ljubljana, Slovenija

\section{Monika Tomazin, dipl. m. s.}

Klinični oddelek za otroško alergologijo, revmatologijo in klinično imunologijo Pediatrična klinika, Univerzitetni klinični center Ljubljana, Ljubljana, Slovenija

Mateja Hren, viš. med. ses., univ. dipl.

org.

Klinični oddelek za otroško alergologijo, revmatologijo in klinično imunologijo Pediatrična klinika, Univerzitetni klinični center Ljubljana, Ljubljana, Slovenija

prispelo / received: 22.6 .2021

sprejeto / accepted: 25. 8. 2021

Čamernik M, et al. Vloga medicinske sestre pri diagnostično-terapevtskih postopkih v alergologiji. Slov Pediatr 2021; 28(4): 216-222. https://doi. org/10.38031/slovpediatr-2021-4-05. 